Journal for

ImmunoTherapy of Cancer

\title{
Nivolumab and dinutuximab beta in two patients with refractory neuroblastoma
}

\author{
Karoline Ehlert, ${ }^{1}$ Ina Hansjuergens, ${ }^{1}$ Andreas Zinke, ${ }^{2}$ Sylke Otto, ${ }^{3}$ Nikolai Siebert, ${ }^{1}$ \\ Guenter Henze, ${ }^{1,4}$ Holger Lode ${ }^{1}$
}

To cite: Ehlert K, Hansjuergens I, Zinke A, et al. Nivolumab and dinutuximab beta in two patients with refractory neuroblastoma. Journal for ImmunoTherapy of Cancer 2020;8:e000540. doi:10.1136/jitc-2020-000540

Accepted 13 April 2020

\section{Check for updates}

C Author(s) (or their employer(s)) 2020. Re-use permitted under CC BY-NC. No commercial re-use. See rights and permissions. Published by BMJ.

${ }^{1}$ Department of Pediatric Hematology and Oncology, Greifswald University Medicine, Greifswald, Germany

${ }^{2}$ Department of Nuclear Medicine, Greifswald University Medicine, Greifswald, Germany ${ }^{3}$ Institute for Diagnostic Radiology, Greifswald University Medicine, Greifswald, Germany ${ }^{4}$ Department of Pediatric Oncology and Hematology, Charité University Medicine Berlin, Campus Virchow Klinikum, Berlin, Germany

Correspondence to Dr Karoline Ehlert; karoline.ehlert@med.unigreifswald.de

\section{ABSTRACT}

Background Neuroblastoma (NB) is the most frequent extracranial solid tumor in children. More than $50 \%$ of patients present with widespread (stage $\mathrm{M}$ ) or refractory disease. In these patients, event-free and overall survival was improved by the addition of the anti-disialoganglioside antibody dinutuximab beta (DB) following multimodal conventional therapy. However, the prognosis of patients with refractory/relapsed NB remains poor. In the past decade, immunotherapy approaches with checkpoint inhibitors were approved for patients with certain malignant diseases such as melanoma or Hodgkin lymphoma. In preclinical models, DB resulted in an upregulation of the programmed cell death protein 1 (PD1) checkpoint in NB cell lines and a combined treatment of DB with a murine anti-PD-1 checkpoint inhibitor showed a synergistic effect in a NB mouse model.

Case presentations Two patients were admitted with refractory metastatic NB. In the 4-year-old girl, NB was diagnosed in 2013. She completed her first-line therapy with a first remission in 2015 , but suffered a relapse in 2017. Treatment with chemotherapy and DB resulted in progressive disease after transient improvement. In the 17-year-old young man, NB was first diagnosed in April 2010. After two local relapses in 2011 and 2014, a metastatic relapse and a large abdominal tumor bulk were found in 2018. Despite transient improvement with multimodal therapy, progressive metastatic disease was observed in May 2019. Both patients had a satisfactory quality of life. Therefore, treatment with DB and nivolumab was performed - in the girl from October 2018 until August 2019, in the young man since June 2019. Tolerance to treatment was excellent. The girl continues to be in complete remission 6 months after therapy was stopped. In the young man, the soft tissue lesions disappeared completely, the skeletal lesions regressed substantially after 9 months of his still ongoing treatment. Conclusions The combination of DB with the checkpoint inhibitor nivolumab led to complete and a very good partial remission in two patients with relapsed/refractory NB. Prospective trials are warranted to clarify the role of this novel approach in a larger number of patients.

\section{BACKGROUND}

Neuroblastoma (NB) is the most frequent, solid malignancy in childhood outside the central nervous system. More than $90 \%$ of children with $\mathrm{NB}$ are diagnosed until the age of 6 years. The presence of MYCN amplification and/or metastatic disease (stage $\mathrm{M}$ ) are considered high-risk features in patients with NB. In this group, 5-year event-free survival is still below $50 \%$ despite multimodal therapy including chemotherapy, surgery, radiotherapy, high-dose chemotherapy with autologous stem cell rescue and maintenance therapy. ${ }^{1}$ Therefore, identifying new treatment strategies for these patients is of major importance.

Disialoganglioside $\left(\mathrm{GD}_{2}\right)$ is a glycolipid of the cell membrane. It is found on all NB cells with limited expression on normal tissue, ${ }^{2}$ and is an established target for immunotherapy in patients with NB.

In the ANBL 0032 study of the Children's Oncology Group, administration of the human/mouse chimeric anti-GD ${ }_{2}$ antibody ch14.18 produced in SP2/0 cells (dinutuximab) in combination with granulocyte macrophage colony-stimulating factor (GMCSF) and interleukin 2 (IL-2) resulted in an improved survival of patients with highrisk NB. ${ }^{3}$ Similarly, two trials of the International Society of Paediatric Oncology European Neuroblastoma (SIOPEN) group showed a benefit for patients with high-risk NB treated with dinutuximab beta (DB). DB is different from dinutuximab as this variant was produced in Chinese hamster ovary cells. This introduced variations in the glycosylation pattern followed by enhanced antibody effector functions. ${ }^{4}$ Improved survival was found in first-line maintenance treatment (HR-NBL-SIOPEN/1 study ${ }^{5}$ ) as well as in patients with relapsed and refractory $\mathrm{NB} .{ }^{6}$

DB was approved by the European Medicines Agency in 2017 for the treatment of patients with relapsed or refractory NB. The primary mechanism of action of $\mathrm{DB}$ is the induction of an antibody-dependent cellmediated cytotoxicity, mediated mainly by 
Table 1 Key details of the patients' diagnosis and treatment

\begin{tabular}{|c|c|c|}
\hline Date & Disease stage & Treatment \\
\hline \multicolumn{3}{|l|}{ 4-Year old girl } \\
\hline $\begin{array}{l}\text { August } 2013 \text { to } 2015 \\
\text { (home country) }\end{array}$ & $\begin{array}{l}\text { Diagnosis of retroperitoneal NB, } \\
\text { stage } 4 \text { (INSS), MYCN amplified } \\
\text { FirstCR }\end{array}$ & $\begin{array}{l}\text { Chemotherapy according to HR-NBL1/SIOPEN (rapid } \\
\text { COJEC, TVD) } \\
\text { HD chemotherapy with busulfan/melphalan and ASCT } \\
\text { Two tumor resections in May } 2014 \text { and July } 2014 \\
\text { Local radiotherapy to the lumbar region } \\
\text { - Immunotherapy with dinutuximab beta and IL-2 }\end{array}$ \\
\hline $\begin{array}{l}\text { January } 2017 \text { to November } \\
2017 \\
\text { (home country) }\end{array}$ & $\begin{array}{l}\text { First relapse, localized advanced } \\
\text { PR }\end{array}$ & $\begin{array}{l}\text { Tumor resection } \\
\text { Chemotherapy according to the RIST trial, partly with } \\
\text { bevacizumab } \\
\text { Second HD chemotherapy with thiotepa/ } \\
\text { cyclophosphamide and ASCT } \\
\text { Second radiotherapy }\end{array}$ \\
\hline $\begin{array}{l}\text { December } 2017 \text { to } \\
\text { September } 2018\end{array}$ & $\begin{array}{l}\text { PR } \\
\text { PR followed by PD }\end{array}$ & $\begin{array}{l}\text { Immunotherapy with dinutuximab beta in combination } \\
\text { with chemotherapy courses from trial NB2004 (N5, N6) } \\
\text { Immunotherapy with dinutuximab beta in combination } \\
\text { with irinotecan/temozolomide }\end{array}$ \\
\hline $\begin{array}{l}\text { October } 2018 \text { to August } \\
2019\end{array}$ & $\begin{array}{l}\text { PD } \\
\text { Second CR in May } 2019\end{array}$ & Immunotherapy with dinutuximab beta and nivolumab \\
\hline $\begin{array}{l}\text { August } 2019 \text { to March } \\
2020\end{array}$ & $\begin{array}{l}\text { Persistent second complete } \\
\text { remission (CR) }\end{array}$ & None \\
\hline
\end{tabular}

\section{7-Year-old young man}

April 2010 to July 2010

- Diagnosis of left adrenal NB, stage 2 (INSS), MYCN non-amplified

- First CR

\begin{tabular}{|c|c|c|}
\hline July 2011 to July 2012 & $\begin{array}{l}\text { First relapse, local } \\
\text { PD in July } 2012\end{array}$ & $\begin{array}{l}\text { Chemotherapy according to the RIST trial (composition } \\
\text { see above) } \\
\text { cymor resection, one course of postsurgical } \\
\text { cyclophosphamide } \\
\text { - Immunotherapy with dinutuximab beta and IL-2 }\end{array}$ \\
\hline July 2012-October 2012 & $\begin{array}{l}\rightarrow \text { PD } \\
\text { Second CR }\end{array}$ & $\begin{array}{l}\text { Chemotherapy according to trial NB2004 (2x N8) } \\
\text { Tumor resection }\end{array}$ \\
\hline February 2014-July 2014 & $\begin{array}{l}\text { Second relapse, local } \\
\text { Third complete remission }\end{array}$ & $\begin{array}{l}\text { Tumor resection } \\
\text { Radiotherapy } \\
\text { - Systemic therapy declined }\end{array}$ \\
\hline June 2018 to May 2019 & $\begin{array}{l}\text { Third relapse, metastatic } \\
\text { PR followed by PD }\end{array}$ & $\begin{array}{l}\text { Chemotherapy according to trial NB2004 (N5/N6 courses) } \\
\text { Tumor resection (nephrectomy and adrenalectomy left) } \\
\text { Local radiotherapy } \\
\text { mIBG-therapy }\end{array}$ \\
\hline June 2019 to ongoing & $\begin{array}{l}>\mathrm{PD} \\
>\mathrm{PR}\end{array}$ & - Immunotherapy with DB and nivolumab \\
\hline
\end{tabular}

ASCT, autologous stem cell transplantation; CR, complete remission; DB, dinutuximab beta; HD, high dose; IL-2, interleukin 2; INSS, International Neuroblastoma Staging System; mIBG, metaiodobenzylguanidine; N5, cisplatin, etoposide, vindesine; N6, vincristine, dacarbacine, ifosfamide, doxorubicin; N8, topotecan, cyclophosphamide, etoposide; NB, neuroblastoma; NB2004, neuroblastoma 2004 protocol (Germany); PD, progressive disease; PR, partial remission; Rapid COJEC, carboplatin, etoposide, cisplatin, cyclophosphamide; RIST, sirolimus, irinotecan, dasatinib, temozolomide; TVD, topotecan, vincristine, doxorubicin. natural killer (NK) cells. ${ }^{7}$ The contribution of macrophages, monocytes and neutrophils to the clinical effect of DB is not clear to date. The cytotoxic response of effector cells is activated by immunoglobulin receptors (FCGR) on the cell surface on recognition of DB bound to NB cells. ${ }^{8}$ FCGR3A is expressed on the surface of NK cells and FCGR2A is expressed on macrophages, monocytes and neutrophils. Frequent clinical adverse effects of DB include the induction of neuropathic pain and capillary leak syndrome. ${ }^{6}$

Whereas passive immune therapy with DB has evolved as a treatment option for pediatric patients with high-risk 

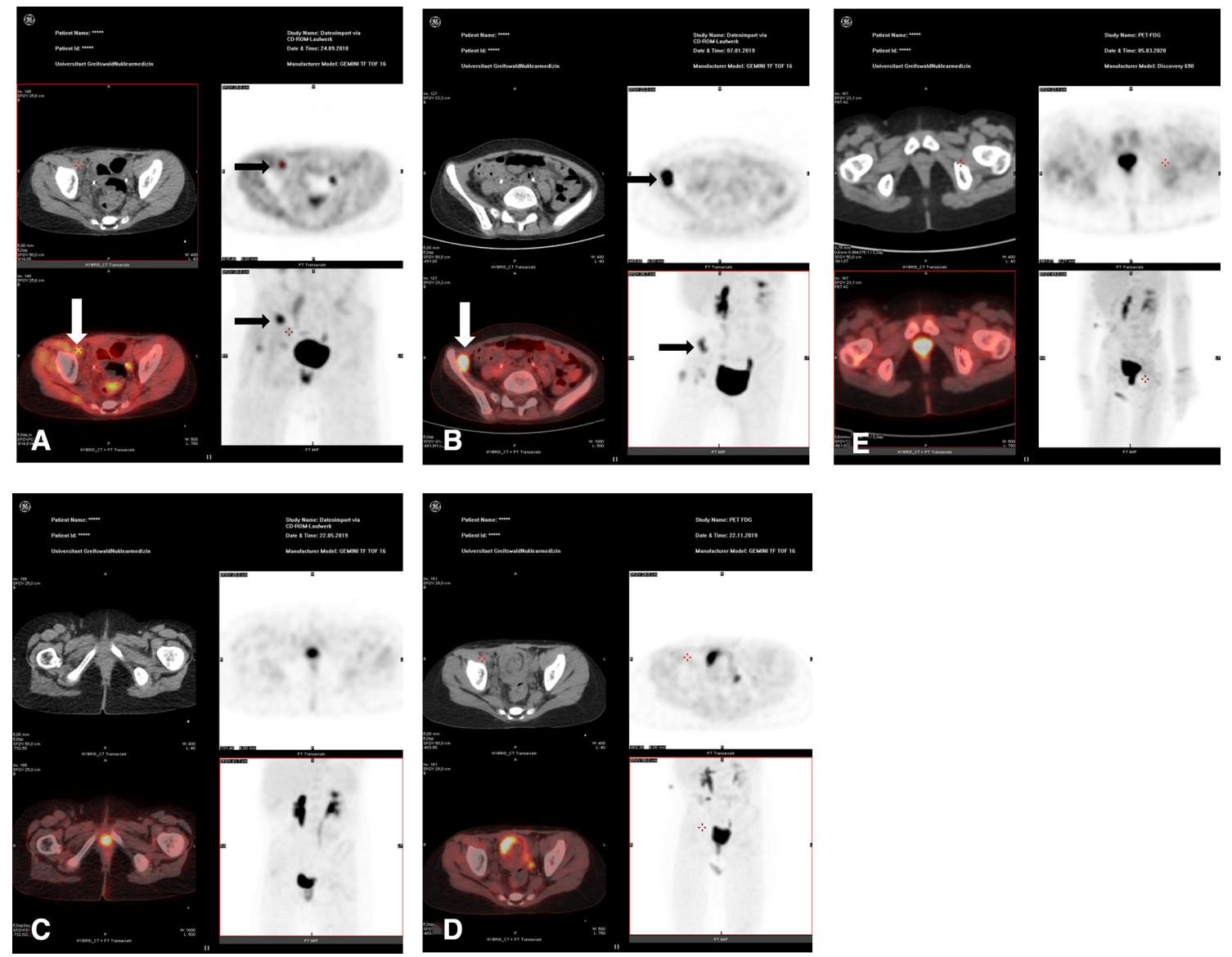

Figure $1 \mathrm{PET} / \mathrm{CT}$ in patient 1. The black and white arrows indicate the most prominent soft tissue metastases in the pelvic and inguinal region. (A) September 2018, prior to therapy with DB and nivolumab. (B) January 2019, pseudoprogression with a more intense PET signal. (C) May 2019. (D) October 2019. (E) March 2020. In C, D and E there is no evidence of the former soft tissue metastases. PET/CT, positron emission tomography/computed tomography.

NB, active immune therapy approaches such as checkpoint inhibitors have been developed and approved for adult patients with cancer. ${ }^{9}$ The first checkpoint inhibitor ipilimumab targeting the CTLA-4 molecule was approved for patients with melanoma in 2011. ${ }^{10}$ Programmed cell death protein 1 (PD-1) is another checkpoint mainly expressed on activated T cells and NK cells. ${ }^{11} \mathrm{PD}-1$ inhibits immune responses after binding to its programmed death ligands, PD-L1 and PD-L2. PD-L1 is expressed on hematopoietic and epithelial cells, PD-L2 on macrophages and dendritic cells. An upregulation of both ligands can be observed in malignant diseases, PD-L1 predominantly in solid tumors, PD-L2 in B cell lymphoma. ${ }^{9}$ In NB, PD-L1 expression is low. However, a constitutive and inducible PD-L1 expression was shown in several cell lines. ${ }^{12} 13$

Nivolumab is a monoclonal antibody that inhibits the PD-1/PD-L1 checkpoint by specifically binding to PD-1 and is approved for the treatment of patients with malignant diseases including melanoma, non-small cell lung cancer and Hodgkin lymphoma.

In a preclinical NB model it was demonstrated that low PD-L1 expression was upregulated by the treatment with DB, and a combined treatment with a murine anti-PD-1 antibody and DB induced a synergistic anti-NB immune response in a syngeneic mouse model. ${ }^{14}$ Therefore, this combination might be a reasonable approach for patients with NB. As both DB and nivolumab lead to immune system activation, autoimmune phenomena are possible adverse effects particularly to be considered with this approach. Here, we report the results of combined treatment with nivolumab and DB in two patients with relapsed/refractory NB.

\section{CASE PRESENTATIONS \\ Patient 1}

In August 2013, a 4-year-old girl was diagnosed with MYCN-amplified, metastatic retroperitoneal NB stage M according to the International Neuroblastoma Staging System (INSS). As the patient's NB was ${ }^{123}$ I-metaiodobenzylguanidine (mIBG)-negative, ${ }^{18} \mathrm{~F}$-fluoro-2-deoxyglucose positron emission tomography/computed tomography $\left({ }^{18} \mathrm{~F}\right.$-FDG PET/CT) was used for tumor assessments. The girl received multimodal high-intensity first-line and relapse treatment (table 1). She was admitted to the University Children's Hospital Greifswald in December 2017 with active disease. From December 2017 until September 2018, she was first treated with a combination of $\mathrm{DB}$ and chemotherapy elements from the NB protocol NB2004. As the girl developed prolonged 


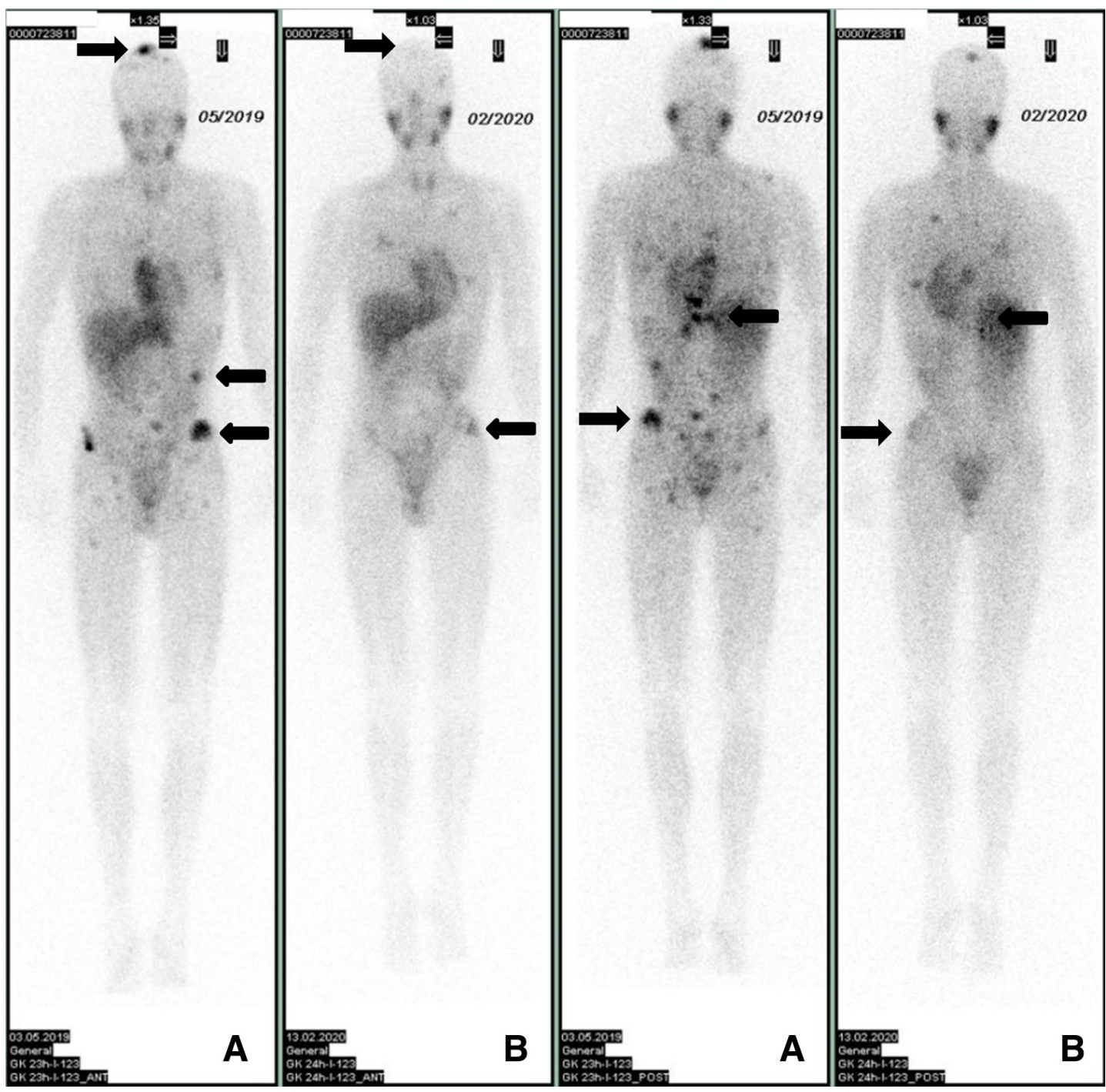

Figure $2 \mathrm{mIBG}$ in patient 2. The black arrows indicate the most prominent skeletal and soft tissue metastases in the pelvic bone, in the skull and in the para-aortal region (level of the 12th thoracic vertebral body). (A) May 2019, prior to therapy with DB and nivolumab. (B) March 2020, substantial regression of the skeletal metastases and resolution of the soft tissue metastases. DB, dinutuximab beta; mIGB, metaiodobenzylguanidine.

periods of granulocytopenia and recurrent urinary tract infections, we decided to continue her treatment with DB and irinotecan/temozolomide. After an initial response she developed progressive disease in September 2018 as demonstrated by MRI and PET/CT (figure 1A). The expression of $\mathrm{GD}_{2}$ was confirmed in September 2018 after obtaining tumor tissue to explore further therapeutic options.

Considering the reduced tolerance to her relapse treatment, but her still good quality of life, we decided to apply a combined immunotherapy using nivolumab and DB. From October 2018 until August 2019, the girl received 19 doses of nivolumab $(3 \mathrm{mg} / \mathrm{kg}$ body weight (BW) every 2 weeks) and 8 courses of DB $\left(100 \mathrm{mg} / \mathrm{m}^{2}\right.$ body surface area in 10 days, every 6 weeks). In January 2019, progressive disease was suspected in routine MRI and PET/CT scans (figure 1B). Nevertheless, we decided to continue treatment, as the general condition of the girl was excellent. Interestingly, PET/CT scans in May 2019 (figure 1C), August 2019, November 2019 (figure 1D) and March 2020 (figure 1E) showed a complete resolution of the disease with no residual tumors in the retroperitoneal and inguinal region. This was confirmed by MRI scans. We decided to stop immunotherapy 3 months after the patient achieved the second complete remission. Autoimmune phenomena were not observed during or after immunotherapy. The girl did not receive any blood products from October 2018 until March 2020. Apart from a single urinary tract infection in December 2018, tolerance to treatment was excellent. She is disease-free, at home with her parents, visits school and is fully active.

\section{Patient 2}

The 17-year-old young man was diagnosed in April 2010 with $M Y C N$ non-amplified NB, INSS stage L, originating from the left adrenal gland. After two local relapses, his disease progressed to stage M in June 2018 with multiple bone metastases and a large abdominal mass at the site 
of the primary tumor. The first-line and relapse treatments followed a high-intensity multimodal approach (table 1). Treatment from June 2018 until May 2019 included chemotherapy according to the high-risk group in neuroblastoma 2004 protocol (Germany), resection of the large abdominal mass with left-sided nephrectomy and local radiotherapy. We intended to proceed to mIBG therapy followed by high-dose chemotherapy and autologous stem cell rescue. However, the therapeutic mIBG scan from May 2019 revealed a considerable increase of bone metastases. As high-dose chemotherapy is not an option in progressive disease, this concept of treatment was abandoned. Detailed analysis of the tumor tissue after resection in January 2019 had confirmed the expression of $\mathrm{GD}_{2}$ and PD-L1.

Despite progressive disease, the patient still had a good quality of life without continuous pain or relevant disabilities. Based on the experience with patient 1 and the exploitation of all conventional therapeutic options, we applied DB and nivolumab. From June 2019 until February 2020, the patient received 19 doses of nivolumab (3 mg/ $\mathrm{kg}$ BW, every 2 weeks) and 7 courses of DB $\left(100 \mathrm{mg} / \mathrm{m}^{2}\right.$ in 10 days, every 6 weeks). In February 2020, we found a substantial regression of skeletal lesions in mIBG scans (figure 2A,B). He is still receiving treatment. The young man had one febrile episode caused by an infection of the central venous line. We did not observe any autoimmune phenomena. He did not receive any blood products from June 2019 until February 2020. His quality of life is excellent. He married in August 2019, is fully active and plans to resume his academic career.

In both patients, tumor markers as catecholamine metabolites in the urine and neuron-specific enolase were checked several times during treatment. However, we did not find any consistent association with the results of the imaging studies.

\section{DISCUSSION}

First-line treatment for patients with high-risk NB involves a multimodal approach combining chemotherapy, surgery, high-dose chemotherapy with autologous stem cell rescue with or without mIBG therapy and external beam radiotherapy. In addition, maintenance therapy with DB is standard of care in high-risk NB. ${ }^{15}$

Patients with refractory disease or multiple relapses of NB have a dismal prognosis when standard treatment approaches have failed. ${ }^{16}$ Immune therapy with DB either alone or in combination with a haploidentical stem cell transplant procedure is an option currently explored for individual patients. ${ }^{17}$

In the past decade, checkpoint inhibitors have gained particular interest in various malignant diseases of adult patients including melanoma, non-small cell lung cancer and Hodgkin lymphoma. ${ }^{18-20}$ Since 2011, seven checkpoint inhibitors have been approved including nivolumab. Based on the observation that DB leads to an upregulation of the PD-1/PD-L1 checkpoint ${ }^{14}$ in a preclinical model with a synergistic therapeutic effect when combined with an anti-PD-1 antibody, we applied this combination in two heavily pretreated patients with relapsed/refractory NB. The outcome was very promising as both patients showed an excellent response to this treatment. In patient 1 , progressive disease was suspected at staging examinations after 3 months of therapy. It is well known, that checkpoint inhibitors may result in pseudoprogression after the first few weeks of treatment due to immunotherapy-induced inflammatory reaction. ${ }^{21}$ Considering pseudoprogression and the excellent general condition of the patient, we decided to continue her treatment as planned. Four months later, all PET-positive lesions had disappeared. The complete response was confirmed by MRI scans. The CR was stable as further PET/CTs at the end of therapy and in the patient's 3-month and 6-month follow-up revealed no evidence of disease. In patient 2, the response to treatment was documented by MRI and mIBG scans. Regression of tumor tissue was clearly seen in the patient's soft tissue lesions and in the bone metastases. As both patients had previous, unsuccessful therapies with DB alone or in combination with IL-2 or chemotherapy, we consider the addition of immune therapy with nivolumab as the decisive element for the favorable outcome documented in our two patients.

\section{CONCLUSIONS}

We report the first results of a combined treatment with nivolumab and DB in two patients with relapsed/refractory NB. The response to treatment was excellent. The first patient is now 6 months after end of therapy in ongoing complete remission. The second patient has reached a partial remission and is still receiving treatment. Treatment-related toxicities were mild and well manageable; in particular, we did not observe any autoimmune phenomena. Both patients have an excellent quality of life and are fully active. These results suggest that combined immune therapy with nivolumab and DB may be a promising strategy to be explored in a prospective clinical trial.

Acknowledgements The authors thank Frank Amtsberg for his technical support.

Contributors KE wrote the original manuscript draft. $\mathrm{GH}, \mathrm{HL}$ and $\mathrm{IH}$ reviewed the draft. AZ and SO contributed and reviewed the imaging studies. HL, GH and NS were closely involved in the conception of this individual treatment approach. All authors read and approved the manuscript.

Funding The authors have not declared a specific grant for this research from any funding agency in the public, commercial or not-for-profit sectors.

Competing interests None declared.

Patient consent for publication Obtained.

Ethics approval Written informed consent was obtained in both patients.

Provenance and peer review Not commissioned; externally peer reviewed.

Open access This is an open access article distributed in accordance with the Creative Commons Attribution Non Commercial (CC BY-NC 4.0) license, which permits others to distribute, remix, adapt, build upon this work non-commercially, and license their derivative works on different terms, provided the original work is 
properly cited, appropriate credit is given, any changes made indicated, and the use is non-commercial. See http://creativecommons.org/licenses/by-nc/4.0/.

\section{REFERENCES}

1 Pinto NR, Applebaum MA, Volchenboum SL, et al. Advances in risk classification and treatment strategies for neuroblastoma. J Clin Oncol 2015;33:3008-17.

2 Svennerholm L, Boström K, Fredman P, et al. Gangliosides and allied glycosphingolipids in human peripheral nerve and spinal cord. Biochim Biophys Acta 1994;1214:115-23.

3 Yu AL, Gilman AL, Ozkaynak MF, et al. Anti-GD2 antibody with GMCSF, interleukin-2, and isotretinoin for neuroblastoma. N Engl J Med 2010;363:1324-34

4 Zeng Y, Fest S, Kunert R, et al. Anti-neuroblastoma effect of ch14.18 antibody produced in $\mathrm{CHO}$ cells is mediated by NK-cells in mice. Mol Immunol 2005;42:1311-9.

5 Ladenstein R, Pötschger U, Valteau-Couanet D, et al. Investigation of the role of Dinutuximab Beta-Based immunotherapy in the SIOPEN high-risk neuroblastoma 1 trial (HR-NBL1). Cancers 2020;12. doi:10.3390/cancers12020309. [Epub ahead of print: 28 Jan 2020].

6 Mueller I, Ehlert K, Endres S, et al. Tolerability, response and outcome of high-risk neuroblastoma patients treated with long-term infusion of anti-GD ${ }_{2}$ antibody ch14.18/CHO. MAbs 2018;10:55-61.

7 Siebert N, Jensen C, Troschke-Meurer S, et al. Neuroblastoma patients with high-affinity FCGR2A, -3A and stimulatory KIR $2 \mathrm{DS}_{2}$ treated by long-term infusion of anti-GD, antibody ch14.18/ $\mathrm{CHO}$ show higher ADCC levels and improved event-free survival. Oncoimmunology 2016;5:e1235108.

8 Cheung N-KV, Sowers R, Vickers AJ, et al. FCGR2A polymorphism is correlated with clinical outcome after immunotherapy of neuroblastoma with anti-GD2 antibody and granulocyte macrophage colony-stimulating factor. J Clin Oncol 2006;24:2885-90.

9 Topalian SL, Drake CG, Pardoll DM. Immune checkpoint blockade: a common denominator approach to cancer therapy. Cancer Cell 2015;27:450-61.
10 Cameron F, Whiteside G, Perry C. Ipilimumab: first global approval. Drugs 2011;71:1093-104.

11 van Dam LS, de Zwart VM, Meyer-Wentrup FAG. The role of programmed cell death-1 (PD-1) and its ligands in pediatric cancer. Pediatr Blood Cancer 2015;62:190-7.

12 Boes M, Meyer-Wentrup F. TLR3 triggering regulates PD-L1 (CD274) expression in human neuroblastoma cells. Cancer Lett 2015;361:49-56.

13 Dondero A, Pastorino F, Della Chiesa M, et al. PD-L1 expression in metastatic neuroblastoma as an additional mechanism for limiting immune surveillance. Oncoimmunology 2015;5:e1064578.

14 Siebert N, Zumpe M, Jüttner M, et al. PD-1 blockade augments anti-neuroblastoma immune response induced by anti-GD $\mathrm{D}_{2}$ antibody ch14.18/CHO. Oncoimmunology 2017;6:e1343775.

15 Simon T, Hero B, Schulte JH, et al. 2017 GPOH guidelines for diagnosis and treatment of patients with neuroblastic tumors. Klin Padiatr 2017;229:147-67.

16 Yi ES, Son MH, Hyun JK, et al. Predictors of survival in patients with high-risk neuroblastoma who failed tandem high-dose chemotherapy and autologous stem cell transplantation. Pediatr Blood Cancer 2020;67:e28066.

17 Illhardt T, Toporski J, Feuchtinger T, et al. Haploidentical stem cell transplantation for Refractory/Relapsed neuroblastoma. Biol Blood Marrow Transplant 2018;24:1005-12.

18 Herrscher H, Robert C. Immune checkpoint inhibitors in melanoma in the metastatic, neoadjuvant, and adjuvant setting. Curr Opin Oncol 2020;32:106-13.

19 Khan M, Lin J, Liao G, et al. Comparative analysis of immune checkpoint inhibitors and chemotherapy in the treatment of advanced non-small cell lung cancer: a meta-analysis of randomized controlled trials. Medicine 2018;97:e11936.

20 Merryman RW, Armand P, Wright KT, et al. Checkpoint blockade in Hodgkin and non-Hodgkin lymphoma. Blood Adv 2017;1:2643-54.

21 Kiriu T, Yamamoto M, Nagano T, et al. Pseudo-progression and the neutrophil-to-lymphocyte ratio in non-small cell lung cancer treated with immune checkpoint inhibitors: a case-control study. Onco Targets Ther 2019;12:10559-68. 